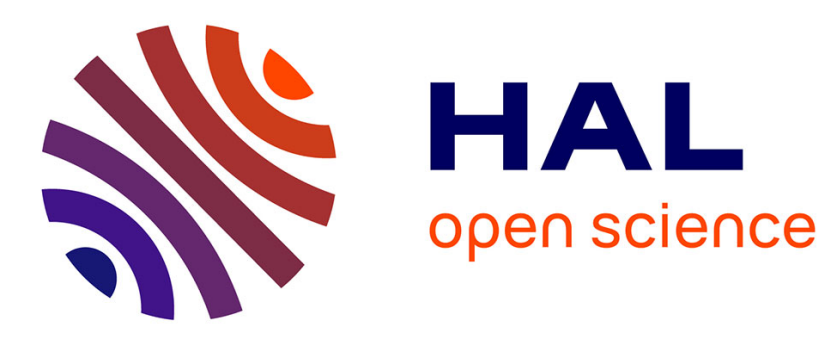

\title{
Experimental investigation of a low Reynolds number flame jet impinging flat plates
}

Eliot Schuhler, Bertrand Lecordier, Jérôme Yon, Gilles Godard, Alexis

Coppalle

\section{- To cite this version:}

Eliot Schuhler, Bertrand Lecordier, Jérôme Yon, Gilles Godard, Alexis Coppalle. Experimental investigation of a low Reynolds number flame jet impinging flat plates. International Journal of Heat and Mass Transfer, 2020, 156, pp.119856. 10.1016/j.ijheatmasstransfer.2020.119856 . hal-02610686

\section{HAL Id: hal-02610686 \\ https://hal.science/hal-02610686}

Submitted on 4 Jun 2021

HAL is a multi-disciplinary open access archive for the deposit and dissemination of scientific research documents, whether they are published or not. The documents may come from teaching and research institutions in France or abroad, or from public or private research centers.
L'archive ouverte pluridisciplinaire HAL, est destinée au dépôt et à la diffusion de documents scientifiques de niveau recherche, publiés ou non, émanant des établissements d'enseignement et de recherche français ou étrangers, des laboratoires publics ou privés. 


\title{
Experimental investigation of a low Reynolds number flame jet impinging flat plates.
}

Eliot Schuhler, Bertrand Lecordier, Jérôme Yon, Gilles Godard, Alexis Coppalle*

Normandie Univ, UNIROUEN, INSA Rouen, CNRS, CORIA, 76000 Rouen, France

\begin{abstract}
A propane burner is used to produce an impinging flame jet onto composite materials in order to understand the thermal degradation of these materials under a high heat flux as a model of reaction to a fire. In the present work, the thermal stress is produced by hot gas exiting from the burner at low Reynolds number and with a short distance between the burner exit and the sample. The temperature, velocity fields and heat fluxes of the impinging jet have been determined experimentally by using thermocouples, the Particle Image Velocity (PIV) technique and a heat flux sensor in order to characterise the thermally stress conditions imposed on the sample. The experimental results are compared to the most valuable analytical solutions found in the literature, in particular Schlichting's theory for the velocity and Sibulkin's and derived relations for the heat transfer to the wall. This allows to better understand what are the main parameters controlling the thermal stress. Most of the analyses have been performed in the stagnation zone and in the wall jet, where the velocity profiles and the heat flux to the wall are well predicted if the thermophysical properties are determined at the hot gas temperatures and low Reynolds number.
\end{abstract}

\section{Keywords}

Impinging jet; Heat transfer; PIV; High temperature

\section{Highlights}

- $\quad$ Particle image velocimetry has been used in a non-reacting hot impinging jet.

- Pyrolysis gas have little to no effect on the impinging jet flow.

- Viscosity effects are negligible compared to kinetic effects in the studied configuration.

\section{Addresses}

Corresponding author:

Alexis Coppalle 


\section{Nomenclature}

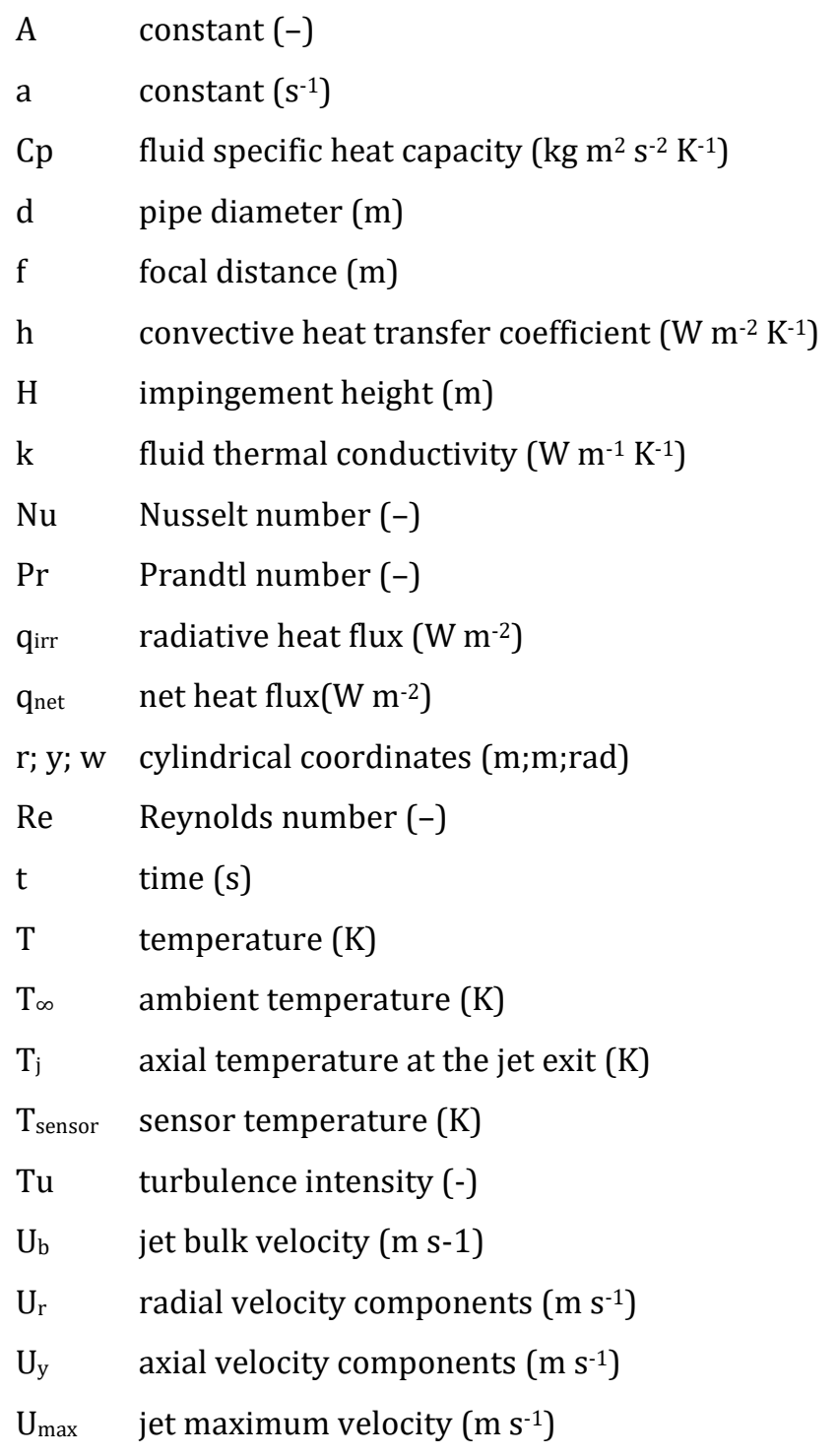

Greek symbols

a absorptivity (-)

$B_{y} \quad$ axial velocity gradient $(-)$

Br radial velocity gradient $(-)$

$\delta_{\mathrm{v}} \quad$ viscous boundary layer thickness $(\mathrm{m})$

$\varepsilon \quad$ emissivity $(-)$

$\mu \quad$ dynamic viscosity $\left(\mathrm{kg} \mathrm{m}^{-1} \mathrm{~s}^{-1}\right)$

$\mathrm{v} \quad$ kinematic viscosity $\left(\mathrm{m}^{2} \mathrm{~s}^{-1}\right)$

$\rho \quad$ fluid density $\left(\mathrm{kg} \mathrm{m}^{-3}\right)$

Other symbols

<> ensemble-averaged quantity

RMS root-mean-square

Acronym

CFRP Carbon Fiber Reinforced Polymer

LDA Laser Doppler Anemometry

PIV Particle Image Velocimetry

Indices

j at the jet exit

0 at the stagnation point

sensor at the sensor surface 


\section{Introduction}

Impinging hot jets and flames are often used to enhance the convective heat flux on walls of solid bodies. This configuration can also be encountered in case of a fire, especially in the event of a fuel line leak. So, in such case, the fire reaction of materials is an important issue, as for example the composites used in aircraft.

A lot of studies have been done on impinging hot jets and are summarized in an exhaustive review by Viskanta [3]. In summary, the flow is decomposed into a free jet zone, a stagnation region, where the output velocity decreases strongly and the convective flux is maximum, and the wall jet region where the velocity is mainly parallel to the wall. The geometry of the impinging and the axis system are shown in Figure 1. An impinging jet is considered to be fully laminar up to a Reynolds number $R e$ of 1000 and fully turbulent for Re greater than 3000. The heat flux and the Nusselt number are functions of the Reynolds number and the relative distance $H / d, H$ being the distance between the jet output and the solid and $d$ being the jet output diameter.

$$
\begin{aligned}
& R e=\frac{d U_{b}}{v} \\
& N u=\frac{h U_{b}}{k_{j}}
\end{aligned}
$$

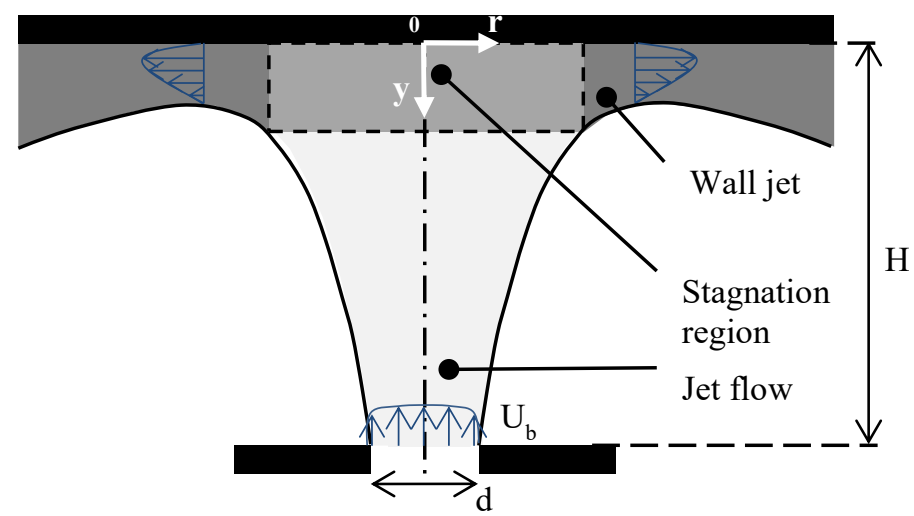

Figure 1 : Scheme of a round jet impinging on a flat wall.

For laminar non-reacting jets, it has been shown [3] that the Nusselt number at the stagnation point is proportional to $R e^{n}$ with $n=0.5$ for a flat exit velocity profile. Polat et al. [4] compared the values of the exponent $n$ that were determined by various numerical and experimental studies and found a strong dispersion of that parameter and shown a dependence on the inlet velocity profile (top-hat or parabolic). For turbulent flows, Donaldson [5] has shown that $N u$ at the stagnation point is still proportional to $R e^{0.5}$. For small distances between exit and plates $(H / d<1)$, radial variations in the Nusselt number are strong for turbulent jets and reduced if the Reynolds number decreases [6]. In this case, the maximum $\mathrm{Nu}$ is on the jet axis and the radial variations are less than $20 \%$ for $r / d<1$.

More recently, detailed measurements of the velocities close to the wall of impinged solids have been obtained with the Laser Doppler Velocimetry (LDV) or Particle Image Velocity (PIV) measurement techniques [7], [8]. They have allowed the determination of the wall shear stress distribution and highlighted a flow reversal in the near wall jet region [7]. They have also shown the presence of large primary turbulent structures that are expected to explain the secondary maximum of the $\mathrm{Nu}$ number located outside the flow axis.

Sibulkin's theory [9] predicts the flow velocities and the convective heat flux at the stagnation point for laminar jets. It has been observed that, at the stagnation point and at small distances $(H / d<5)$, the heat transfer is in good agreement with Sibulkin's laminar theory for a Reynolds number less than about 2000 [3]. For large distances $(H / d>8)$, a free-jet turbulence is developed that increases the convective heat transfer. Sibulkin's relations are still in agreement with experimental results, if the initial turbulent intensity in the free jet is taken into account as an enhancement factor $[3,10]$. 
In the case of flame jets, one finds not as many studies as for isothermal jets. Most of the studies have dealt with solid bodies engulfed in the combustion zone or just above [11]. However, in the work of Van der Meer [10], similarly to the present study, the burner configuration permits the combustion to be achieved before the exit of the hot fluid. Gas temperatures measurements were performed using thin thermocouples, the axial velocities were performed with LDV technique and the heat flux has been measured using a Gardon gauge.

The heat transfer law from non-reacting impinging jets has been used as a starting point to determine the $\mathrm{Nu}$ number at the stagnation point in the cases of hot flows exiting from the burner. The obtained values are in good agreement with the ones determined from the experimental Gardon gauge measurements for plates at small $H$ distances from the burner exit. In Van de Meer's work, the influences of the Reynolds number and the burner-to-plate distance $(H / d)$ on the Nusselt value where also evaluated. This work has also shown that the convective heat transfer for flame jets is in good agreement with the results of isothermal jets if the thermophysical properties of the fluid are defined at the temperature corresponding to the average enthalpy over the boundary layer. Also in flame jet configurations, Remie [12,13] has developed an analytical solution for the heat transfer of a flame jet on a plate, far from the plate and closer, in the viscous boundary layer.

In the present study, a propane burner has been built in order to analyse the fire reaction of carbon fibre reinforced polymers (CFRP). It consists of a combustion chamber and a flame tube. The combustion is achieved in the chamber, which is connected to the flame tube allowing the exit of the hot jet of combustion products to be channelled on small size samples. It has been specifically designed to analyse fire reaction of aeronautic composites, so the tests are performed with a hot flow at the flame tube exit with a temperature greater than $1000{ }^{\circ} \mathrm{C}$ and with a total heat flux equal to $106 \mathrm{~kW} \cdot \mathrm{m}^{-2}$, these conditions being close to the standard-test ones [1], [2]. These conditions were obtained with particular values of the flow rates in the combustion chamber (air and fuel gas) and for samples at a short distance $H / d$ from the flame tube exit. Parameters, $R e$ and $H / d$ were fixed, in consequence Nusselt effect has not been investigated. In counterpart, the aim of the present work is to analyse the heat transfer on the wall of composite samples (or steel plate), with an evaluation of the respective radiative and convective contributions.

First, the test rig and the measurement methods will be presented. Then, the results of temperature and velocity at the flame tube exit will be given and discussed. The characterisation of the near wall flow has been done using a steel plate, however the effect of a reactive wall on the gas flow has been also analysed using a composite plate. In the last part of this work, results given by the analytical approaches, as described above, are compared to experimental values.

\section{Experimental set-up}

\subsection{Test rig}

The burner used in this study was designed and built in order to produce a heat flux ranging from $75 \mathrm{~kW} \cdot \mathrm{m}^{-2}$ up to $200 \mathrm{~kW} \cdot \mathrm{m}^{-2}$ on samples. This experimental set-up, shown in Figure 2, consists of a combustion chamber topped by an insulated flame tube of $500 \mathrm{~mm}$ long and $35 \mathrm{~mm}$ diameter. The combustion chamber is fuelled by propane and air at the bottom. The lower part of the tube includes a secondary air inlet. The flow rate is fixed at 1.17 g.s $\mathrm{s}^{-1}$ for primary air, $0.40 \mathrm{~g} . \mathrm{s}^{-1}$ for secondary air and 0.095 g.s $\mathrm{s}^{-1}$ for the propane to produce a stoichiometric non-premixed flame. This ratio between primary and secondary air inlets is chosen to ensure the stability of the flame in the combustion chamber. The flow rates are controlled by thermal mass flow meters (Bronkhorst manufacturer). Before each test, the heat flux is measured using a water-cooled heat flux sensor (Captec manufacturer), and a temperature control of the exit flow is also performed using a comb of $1 \mathrm{~mm}$ diameter thermocouples. The burner design and the operating conditions allow to produce a non-reacting hot gas jet at the tube outlet with a bulk velocity of $U_{b}=8 \mathrm{~m} . \mathrm{s}^{-1}$ and a temperature of $\mathrm{T}_{\mathrm{j}}=1635 \mathrm{~K}$. The operating conditions are summarised in Table 1 and the Reynolds number based on the bulk velocity is Re $=1500$ which corresponds to a transitional flow. 
Table 1 : Operating condition of the burner.

\begin{tabular}{cccccc}
\hline $\begin{array}{c}\text { Propane } \\
\left.\text { flow (g.s } \mathrm{s}^{-1}\right)\end{array}$ & $\begin{array}{c}\text { Primary air } \\
\text { flow }\left(\mathrm{g} \cdot \mathrm{s}^{-1}\right)\end{array}$ & $\begin{array}{c}\text { Secondary air } \\
\text { flow }\left(\mathrm{g} \cdot \mathrm{s}^{-1}\right)\end{array}$ & $\begin{array}{c}\text { Temperature at } \\
\text { the outlet } \mathrm{T}_{\mathrm{j}}(\mathrm{K})\end{array}$ & $\begin{array}{c}\text { Bulk velocity } \\
\mathrm{Ub}_{\mathrm{b}}\left(\mathrm{m} \cdot \mathrm{s}^{-1}\right)\end{array}$ & $\begin{array}{c}\text { Heat flux } \\
\left(\mathrm{kW} \cdot \mathrm{m}^{-2}\right)\end{array}$ \\
\hline 0.095 & 1.17 & 0.4 & 1635 & 8 & 106 \\
\hline
\end{tabular}

The fast degradation of the composite materials, typically 150s, makes the velocity and temperature measurement at the vicinity of the samples difficult to perform, in particular due to the deformation of the material. Thus, in a first step, the velocity and temperature measurements are made with the hot jet impinging a $0.02 \mathrm{~m}$ thick steel plate coated with a black high-temperature-resistant paint. This configuration permits to design and to optimise the velocity and thermocouple measurements in the hot jet, and then to carry out measurement with composite samples. For each test, the impinged wall is placed $17 \mathrm{~mm}$ above the burner outlet, corresponding to $H / d$ ratio equal to 0.5 .

\subsection{Velocity measurement with PIV}

Zirconium oxide particles were injected into the primary air of the combustion chamber to ensure a regular and uniform seeding from the flame tube outlet up to the sample wall. The laser light sheet used for PIV velocity measurements is produced by a double-cavities Nd :YAG pulsed laser operating at $10 \mathrm{~Hz}$. The power measured at the laser output is $145 \mathrm{~mJ}$ at $532 \mathrm{~nm}$, allowing a sufficiently high Mie scattering signal by the seeding particles. The laser sheet perpendicular to the impinged wall is produced by an optical assembly consisting of a spherical lens $(\mathrm{f}=100 \mathrm{~mm})$ and a cylindrical lens $(\mathrm{f}=30 \mathrm{~mm})$.

The PIV images are recorded by a CCD camera (Imager Pro X) with a resolution of $2048 \times 2048$ pixels and equipped with an $85 \mathrm{~mm}$ Nikkor lens. The spatial resolution is $18.7 \mu \mathrm{m} / \mathrm{px}$ for a $38.3 \times 18.7 \mathrm{~mm}^{2}$ field of view. In order to reject on the images, the parasite signals due to the soot and hot walls emissions, an interference filter centred at $532 \mathrm{~nm}$ is placed in front of the lens. The interval between two laser pulses has been optimised to ensure accurate velocity measurement in the near-wall area. Thus, the time between the openings of the two camera shutters is fixed at $10 \mu \mathrm{s}$. The opening time is $4 \mu \mathrm{s}$ for the first image and $60 \mathrm{~ms}$ for the second image. A number of 3000 pairs of images is recorded for the measurements with the steel plate and of 1000 pairs of images for the composite samples. In the latter case, the degradation of the samples is fast, so the velocity fields are computed in batches of 50 consecutive image pairs. In order to process images and calculate the velocity fields, the software DynamicStudio is used with the AdaptivePIV algorithm. An optimisation of the window size has been performed for the near-wall region. Considering the set-up characteristics and the flow velocity, final interrogation window size has been fixed at $12 \times 12$ pixels, thus leading to a $0.22 \times 0.22 \mathrm{~mm}^{2} \mathrm{spatial}^{2}$ resolution.

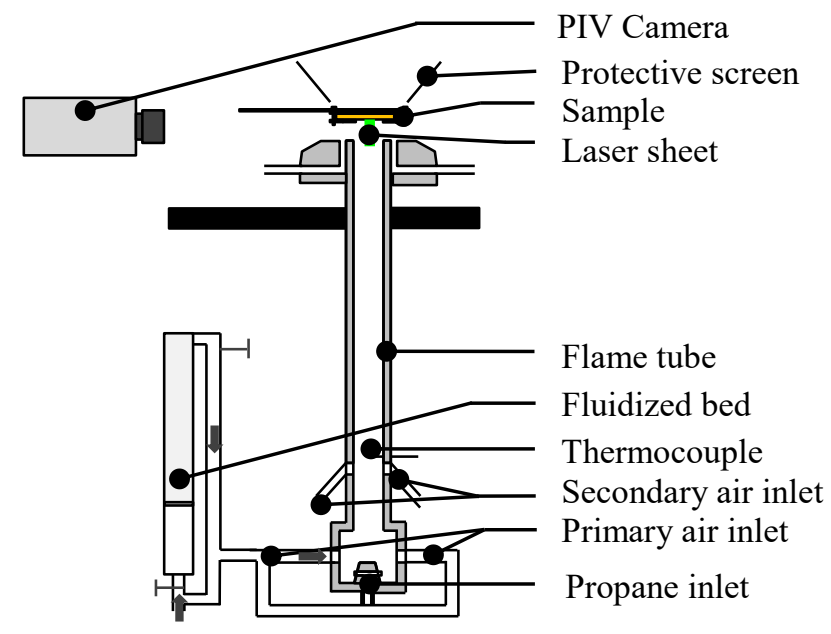

Figure 2 : Schematic representation of the burner and the PIV set-up. 


\subsection{Temperature measurement using thermocouple}

For the tests conducted with a steel plate as impinged wall, the gas temperature is measured using a $50 \mu \mathrm{m}$ diameter thermocouple of type B. The temperature measurements were taken along a wall-parallel traverse $(y / d=0.47)$ and along six wall-normal traverses between the jet centreline and $r / d=0.85$. The locations of the measurements are reported in Figure 3. At each location, 150 temperature samples were taken at $10 \mathrm{~Hz}$ in order to calculate the mean and rms values. A correction of the measured temperature is performed based on the steady state equation described in [16] for the radiative loss.

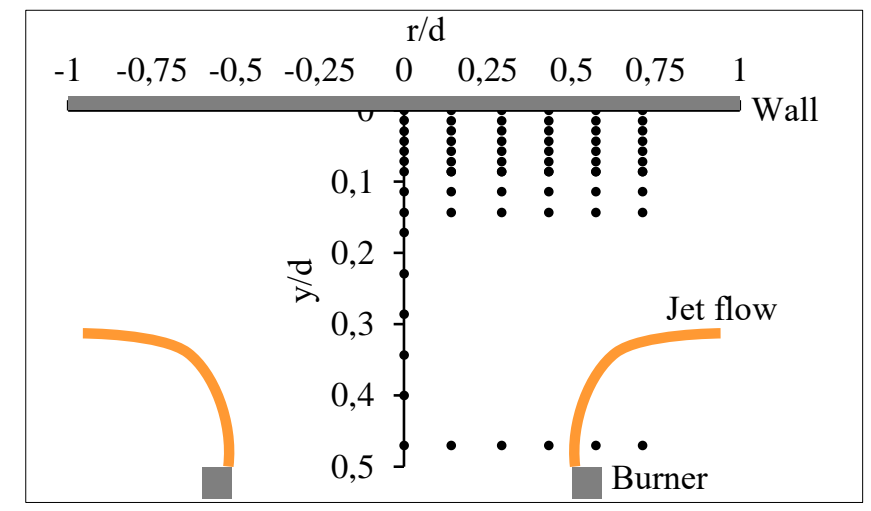

Figure 3 : Positions of the temperature measurements in the impinging jet.

\subsection{Heat flux measurement at the stagnation point}

Before each test, the averaged heat flux is measured during $300 \mathrm{~s}$ using a Gardon-type water-cooled heat flux sensor [14]. More details about the Gardon-type sensor are given by Carlomagno and Ianiro [15]. This sensor allows the measurement of the net heat flux on a $10 \mathrm{~mm}$ diameter sensible element, and it is mounted on a plate of the same size as the sample holder. After the thermal stabilisation of the burner, it is placed in the hot jet at the same location of the sample. After a few seconds of heating, the gauge experiences a steady state heat flow rate, as shown in Figure 4, and a constant temperature. The measured net heat flux can be described by eq. (3) :

$$
\mathrm{q}_{\text {net }}=\alpha_{\text {sensor }} \mathrm{q}_{\text {irr }}-\varepsilon_{\text {sensor }} \sigma \mathrm{T}_{\text {sensor }}^{4}+\mathrm{h}\left(\mathrm{T}_{\mathrm{j}}-\mathrm{T}_{\text {sensor }}\right)
$$

where $q_{\text {irr }}$ is the radiative heat flux, and $h$ the convective heat flux coefficient. $\alpha_{\text {sensor }}$ and $\varepsilon_{\text {sensor }}$ are the absorptivity and emissivity factors of the sensor surface, which are supposed to be equal. The manufacturer's value being $\varepsilon_{\text {sensor }}=0.94$. As the device is water-cooled, the temperature of the sensor surface $T_{\text {sensor }}$ does not exceed $325 \mathrm{~K}$, leading to low radiative losses compared to the net heat flux of 106 kW.m ${ }^{-2}$.

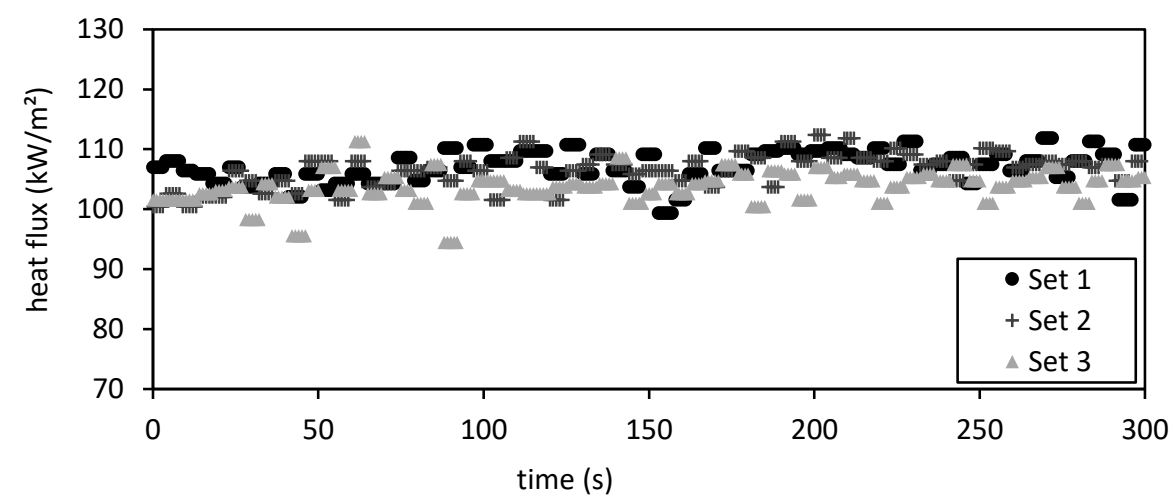

Figure 4 : Measurement of the heat flux during time, for four different tests. 
An additional measurement has been made with the use of a $0.5 \mathrm{~mm}$ thick calcium fluoride $\left(\mathrm{CaF}_{2}\right)$ window on the heat flux sensor in order to evaluate the radiative heat flux $q_{i r r}$. This result is used to calculate the heat transfer coefficient $h$. However, the so determined value of radiative heat flux has to be considered with caution as the window temperature is not known, and consequently the heat flux received by the sensor from the window radiation cannot be corrected and $q_{\text {irr }}$ might be slightly overestimated. The transmission of the window is over $70 \%$ up to a wavelength of $11 \mu \mathrm{m}$.

\section{Experimental results}

\subsection{Flame tube exit conditions}

Figure 5 (a) to (d) show the measured velocities at $2 \mathrm{~mm}$ downstream of the pipe exit. The axial velocity measured at the centre of the jet is $U_{\max }=8.7 \mathrm{~m} . \mathrm{s}^{-1}$, corresponding to $U_{\max } / U_{b}=1.09$. Regarding the axial velocity profile, these results are very similar to those obtained in other experiments $[7,8]$. However, the flow presents a lateral spreading, as shown by the radial velocity profile given in Figure 5 (c), which results the short distance $H / d=0.5$ between the tube exit and the sample wall given. These exit conditions will be used to calculate the velocity profile along the jet centreline and the heat flux at the stagnation point.

(a)

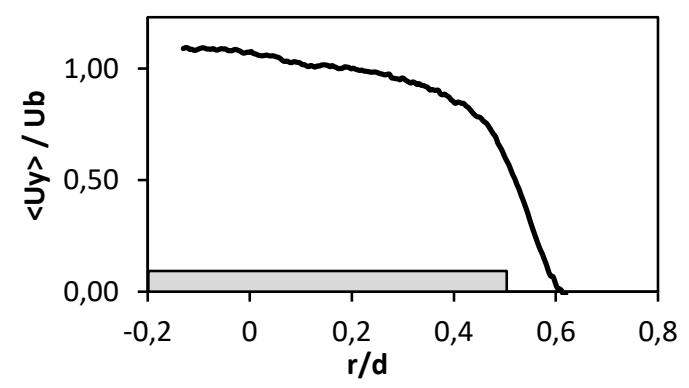

(c)

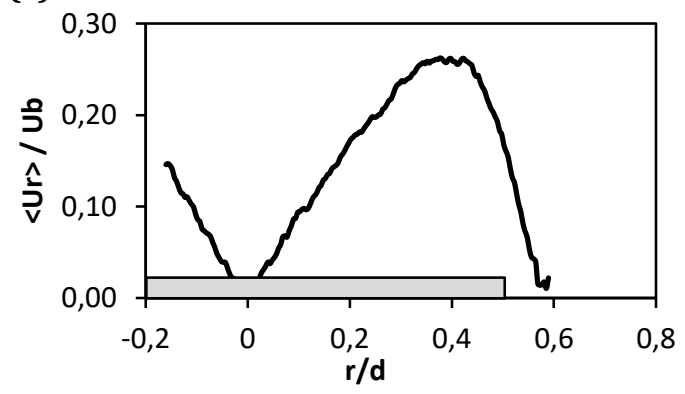

(e)

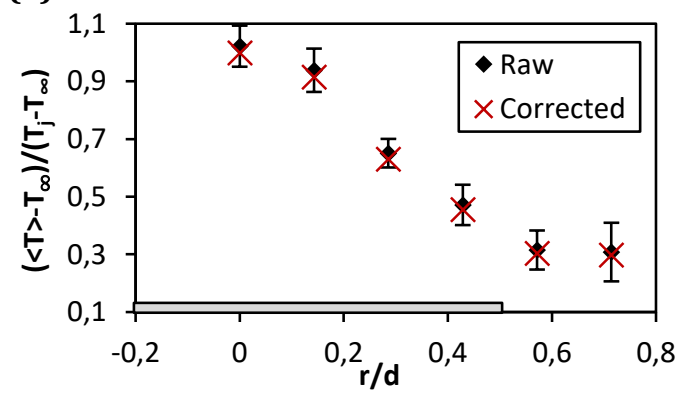

(b)

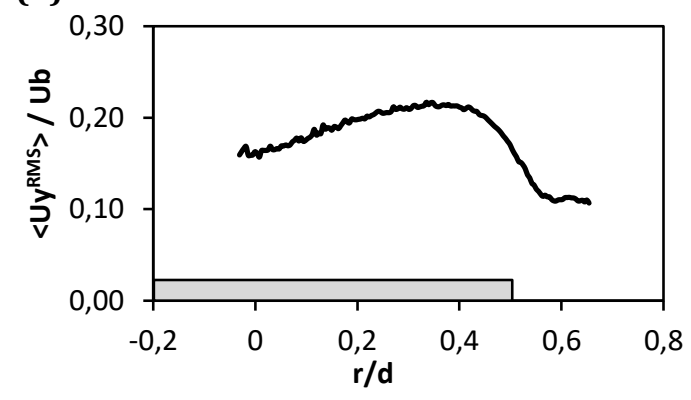

(d)

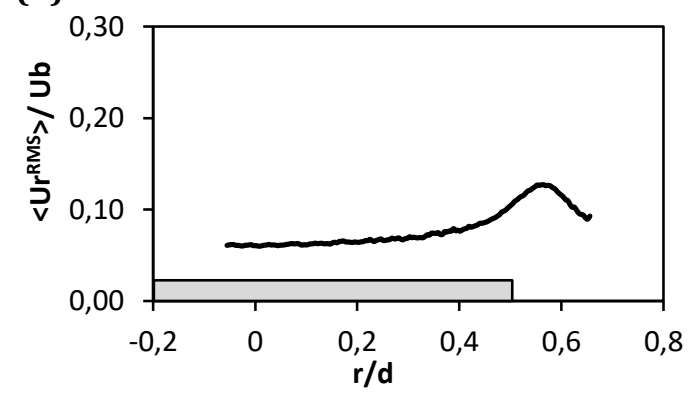

(f)

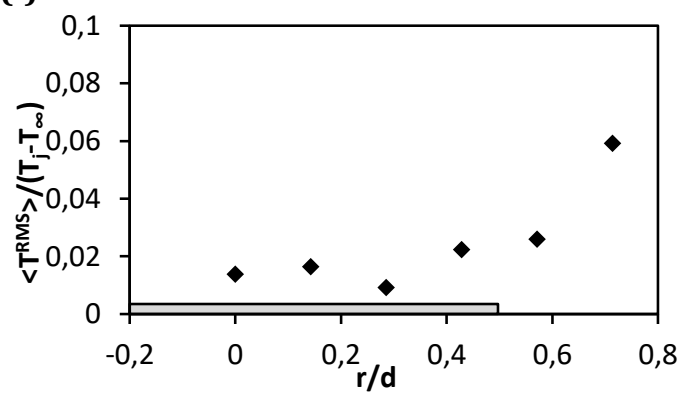

Figure 5 : (a) Mean and (b) fluctuating axial velocity, (c) mean and (d) fluctuating radial velocity, (e) mean and (f) fluctuating temperature. Measurements at $2 \mathrm{~mm}$ downstream of the flame tube outlet. 
Figure 5(e) and (f) show the measured temperatures along the same line. The axial temperature at the jet exit is $T_{j}=1635 \mathrm{~K}$. The high temperature values may lead to radiative loss for the thermocouple. Therefore, a correction of the measured temperature is necessary to obtain the gas temperature. This correction is performed on the basis of a steady state temperature at the junction as described in [16], and using the measured velocity. The maximum radiative loss needs a thermocouple temperature correction of $1.2 \%$.

The dimensionless temperatures shown in Figure 5 are calculated with the expression $\left(T-T_{\infty}\right) /\left(T_{j}-T_{\infty}\right)$ where $T_{\infty}$ is the ambient temperature. As for the velocity measurements, temperature measurements are not made exactly at the tube exit but $2 \mathrm{~mm}$ downstream, so the temperature profiles show also a radial spreading.

Both radial velocity and temperature profiles show little fluctuation at the centre of the jet. In contrast, the axial velocity shows a relatively high amount of fluctuation with $\left\langle U_{y}{ }^{R M S}\right\rangle / U_{b}=16 \%$ at the centre of the jet and $21 \%$ in the shear layer.

\subsection{Near wall flow characterization}

The Figure 6 presents the mean and fluctuating velocities in the plane perpendicular to the impinged wall and passing through the centreline of the pipe. The dashed lines drawn on the velocity fields indicate the locations of the profiles perpendicular to the wall that will be given in Figures 7-9. The velocity measurements presented in this section correspond to the non-reactive wall case (i.e. steel plate).

The average velocity fields presented in Figure 7 show the mains characteristics of the impinging jets that have been described in the state of the art. There is a stagnation zone close centred at $r / d=0$ and from each side $(r / d>0.4)$ a wall jet region. However, the free jet above the outlet of the tube is almost non-existent. At large distances $H / d$ between the outlet and the plate, as found in other works [8,12], the jet exhibits a free stream zone with a constant axial velocity $U_{y}$ followed by a linear decrease down to zero at the wall. In this work, the $H / d$ ratio is small $(H / d=0.5)$. The wall does not allow the free jet to develop fully, and thus, unlike the works cited above, the axial velocity profile at the centre of the jet, which is plotted in Figure 7, is continuously decreasing. For a central zone corresponding to $r / d<0.5$ and close to the wall, the velocity decrease is linear with a constant slope $\beta_{y}=3.13$. This linear behaviour is highlighted by the black plain lines in Figure 7.

$$
\frac{\langle U y\rangle}{U_{b}}=\beta_{y}\left(\frac{y}{d}\right)
$$

Figure 7 also presents the radial component of the velocity $<U r>/ U_{b}$, the black dashed lines representing the position $\delta_{v}$ of the local maximum radial velocity. One can note that the position of maximum radial velocity is almost constant with $\delta_{v}=0.047 \mathrm{y} / \mathrm{d}$. Moreover, for this particular position $y=\delta_{v}$, one can observe a linear growth in the radial velocity with increasing $r / d$. A constant, $\beta_{r}=1.85$, can be defined according to eq. (5).

$$
\frac{\langle U r\rangle_{\delta_{v}}}{U_{b}}=\beta_{r}\left(\frac{r}{d}\right)
$$

Figure 8 shows that, in the stagnation zone and close to the wall, the fluctuations are low for the axial velocity. However, they are higher in three other parts of the flow. Close to the jet exit, the axial velocity fluctuations are important. These high fluctuations at the outlet are due to the length of the flame tube that is not long enough to totally dampen the low-frequency turbulent structures generated in the combustion chamber. Outside the wall jet layer, the velocity fluctuations are also high, mainly in the shear 
layer due to the mixing with ambient air. Finally, high fluctuations of the radial velocity are observed close to the wall.

However, very close to the wall, rms values for the velocity are not accessible due to the low number of validated vectors in that region. The calculation of the rms values does not converge in this near-wall area and thus they are not presented in the Figure 8.
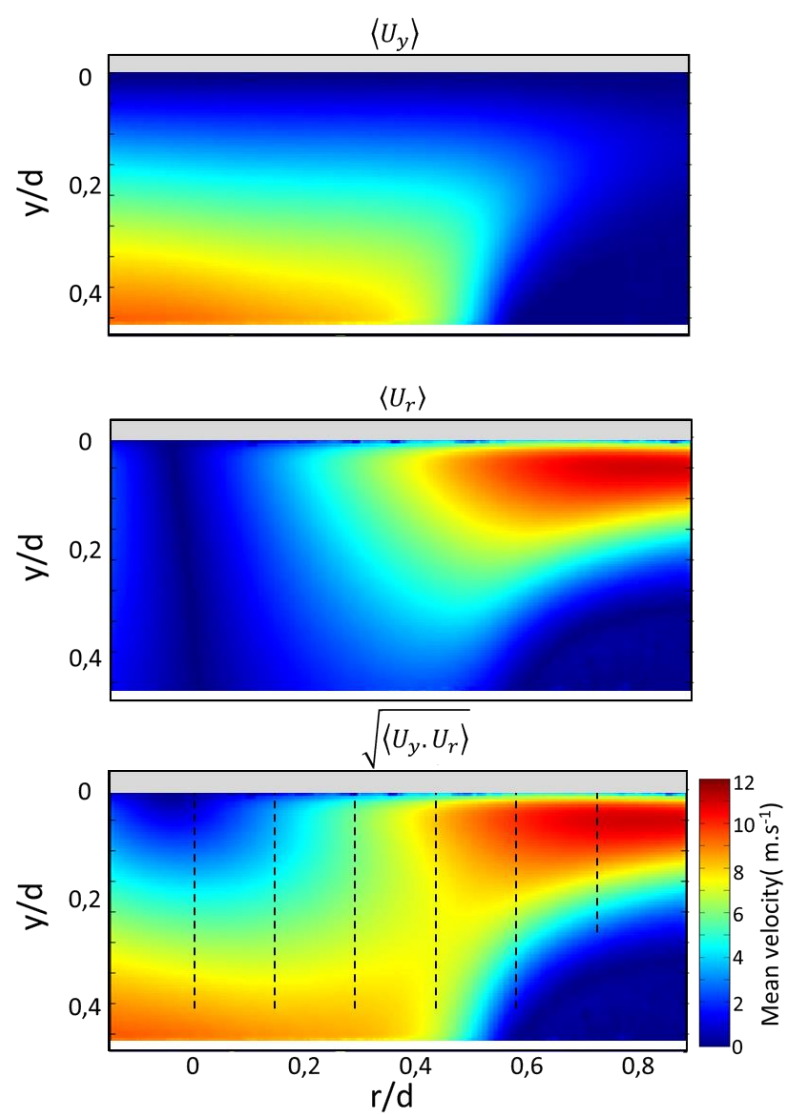
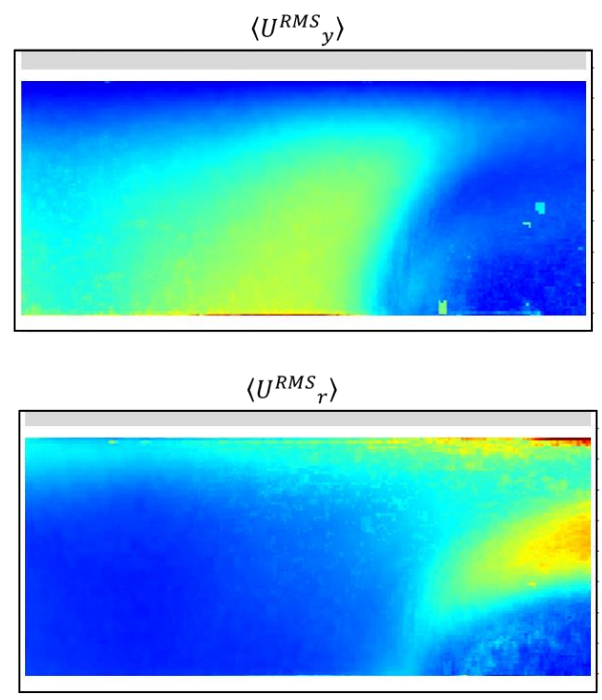

$\left\langle U^{R M S}\right\rangle$

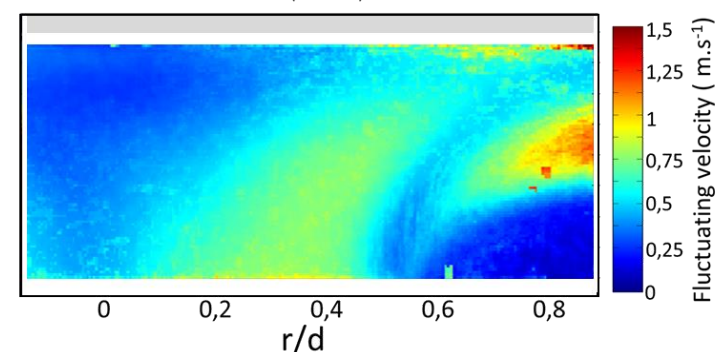

Figure 6: Mean and fluctuating velocity fields, in the plane perpendicular to the impinged wall and passing through the centreline of the pipe and in the case of the steel plate. The dashed lines show the locations of the profiles perpendicular to the wall reported in Figure 7-9. 


$$
\langle\boldsymbol{U} \boldsymbol{y}\rangle / \boldsymbol{U}_{\boldsymbol{b}}
$$
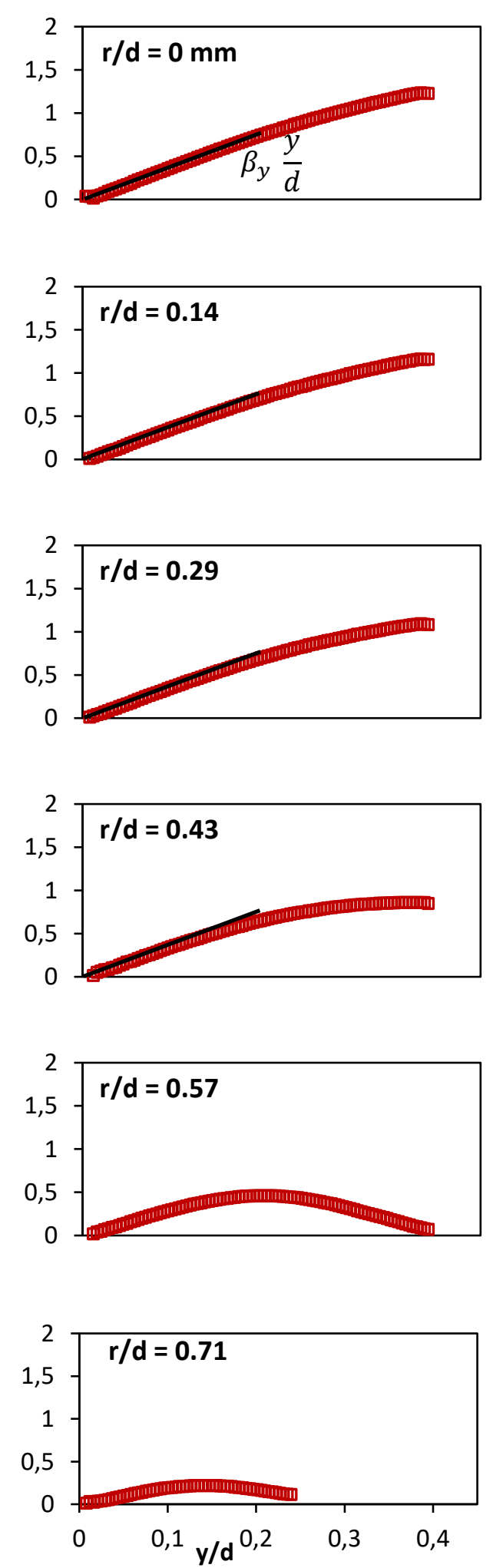

$\langle\boldsymbol{U} \boldsymbol{r}\rangle / \boldsymbol{U}_{\boldsymbol{b}}$
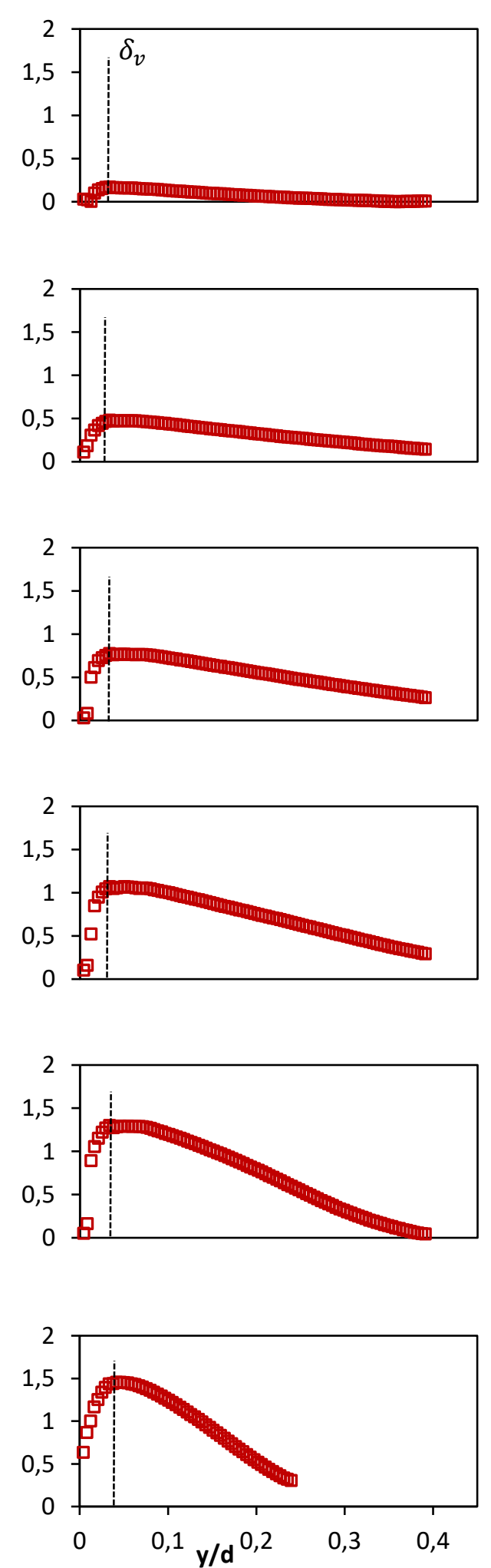

Figure 7 : Mean axial and radial velocities, left and right graph respectively, at different radial positions. 
$\left\langle U_{y}^{R M S}\right\rangle / U_{b}$
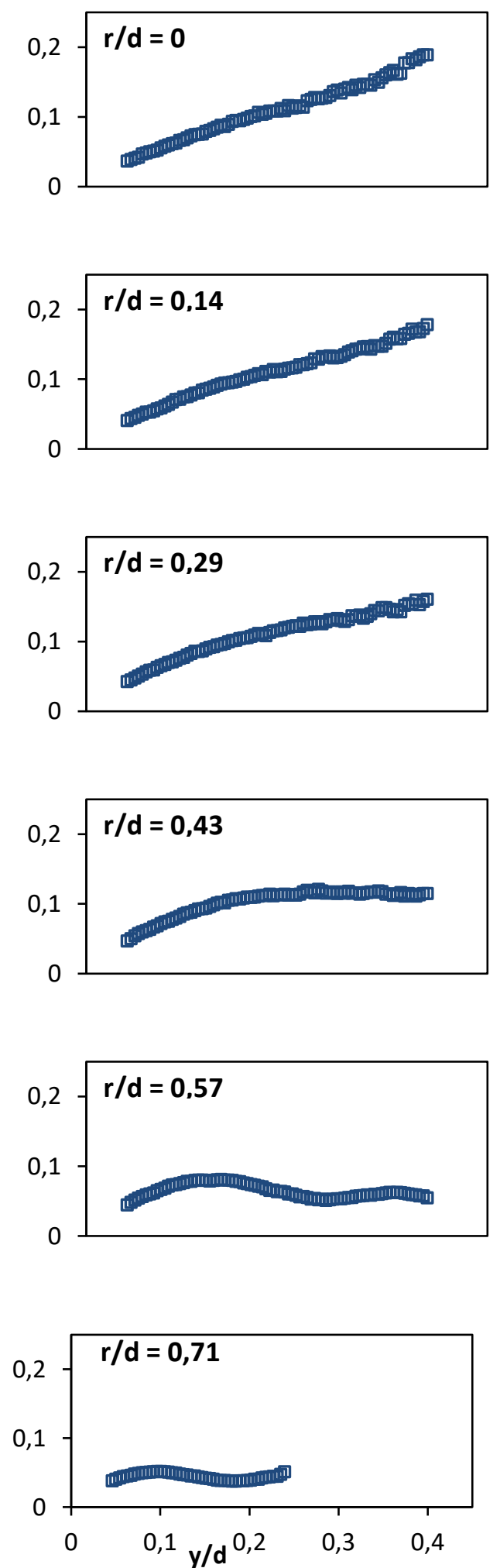

$\left\langle U_{r}^{R M S}\right\rangle / U_{b}$
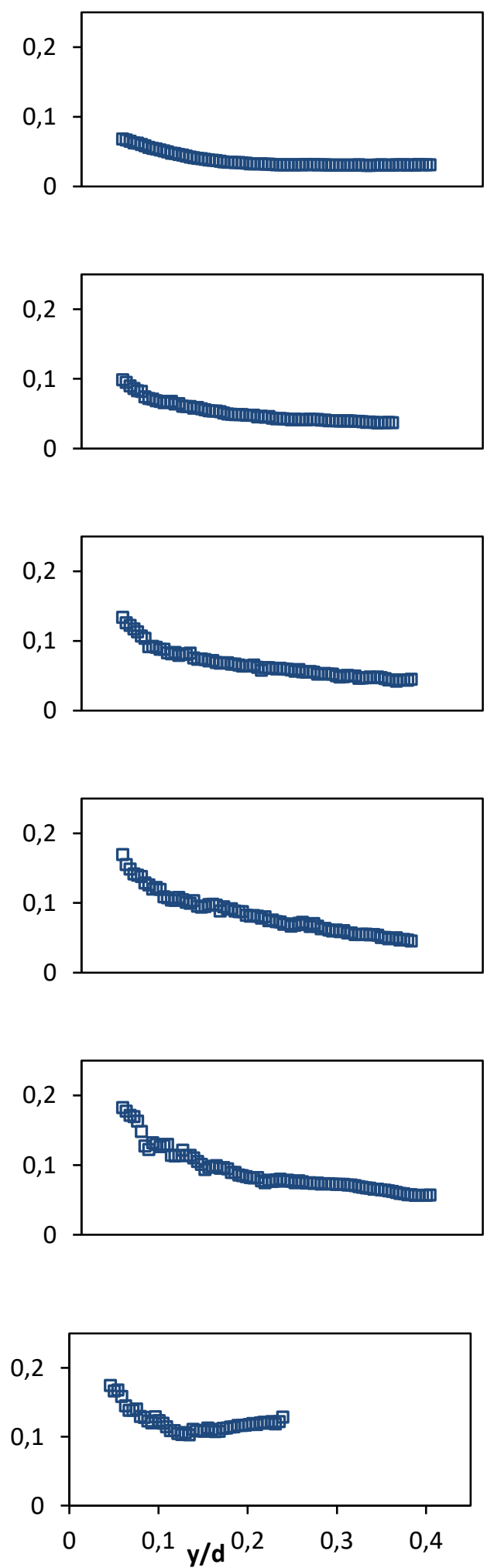

Figure 8 : Fluctuating axiale and radial velocity, left and right graph respectively, at different radial positions. 
Figure 9 shows mean temperatures for different radial positions between $r / d=0$ and 0.71 . In the main part of the stagnation zone $(r / d<0.43)$ and not in the vicinity of the wall, the temperature is quasiuniform. However close to the sample, the hot jet flow reaches the wall temperature over a very short distance, less than $0.5 \mathrm{~mm}$. In the wall jet region $(r / d>0.43)$, the thermal boundary layer thickness $\delta_{\mathrm{T}}$ is slightly increasing with the distance $r / d$, as shown by the dashed lines on Figure 9 . Its maximum value, at $r / d=0.71$, is very close to the $\delta_{\mathrm{v}}$ value (see Figure 7). For higher distances to the wall $\left(y / d>\delta_{T}\right)$ the temperature is slowly decreasing away from the thermal boundary layer.

$\left(<T>-T_{\infty}\right) /\left(T_{j}-T_{\infty}\right)$
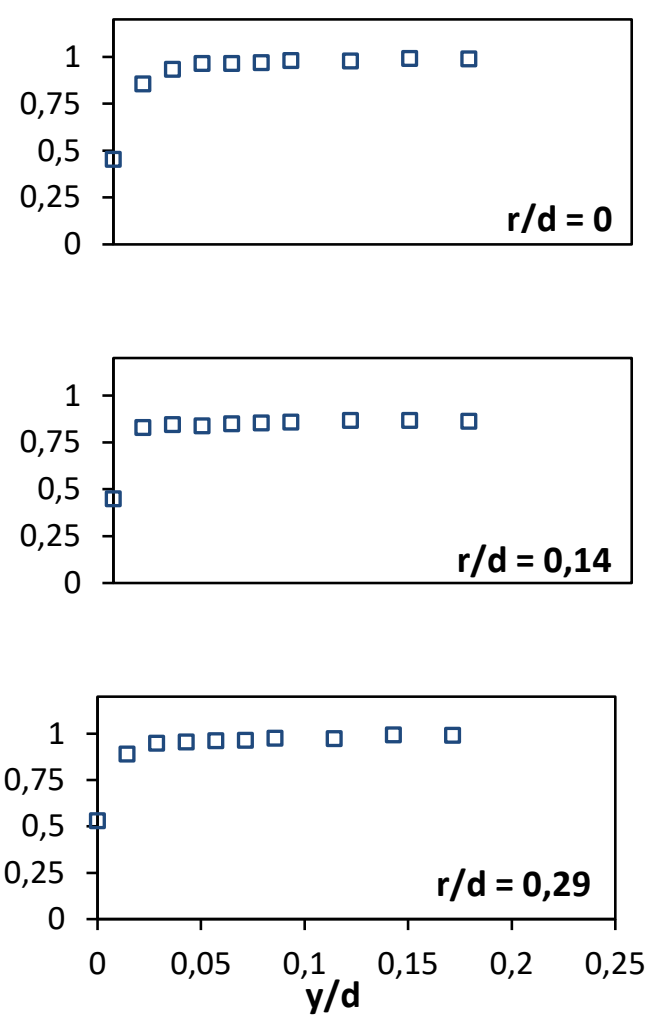

$\left(<T>-T_{\infty}\right) /\left(T_{j}-T_{\infty}\right)$
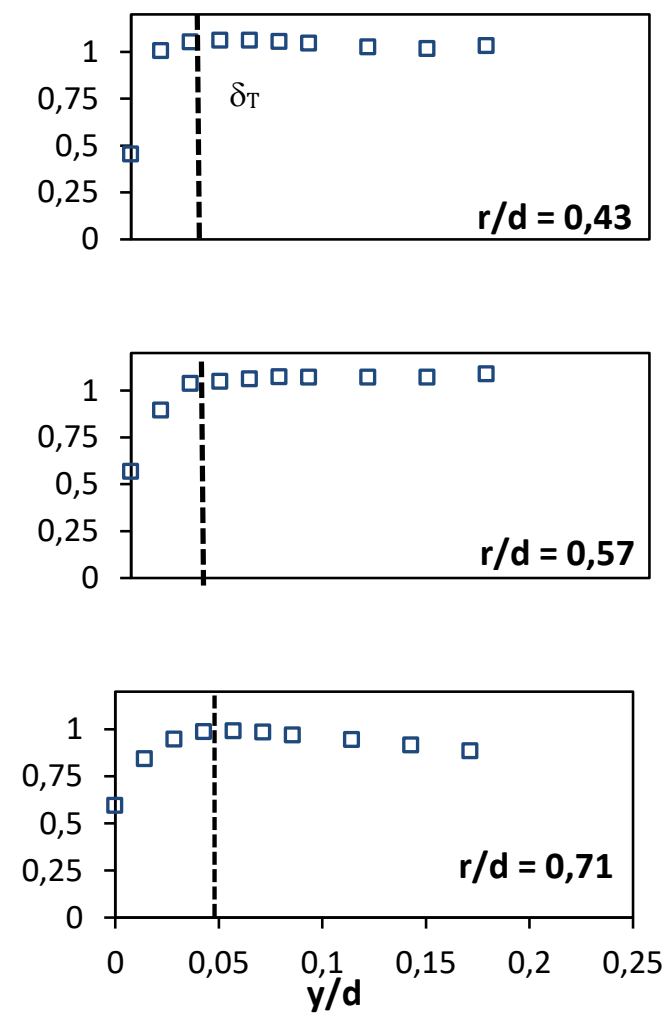

Figure 9 : Temperature measurement performed at different radial positions in the stagnation region.

\subsection{Effect of a reactive wall on the gas flow}

In the case of a flammable material impinged by a fire, one can expect the formation of pyrolysis gas to affect the flow in the near-wall region [17]. Thus, in order to study the behaviour of the hot flow with a reactive wall, velocity measurements have been performed on a composite material, a $4.5 \mathrm{~mm}$ thick carbon/epoxy composite.

During the velocity measurement, the composite samples are completely consumed over $100 \mathrm{~s}$, and the total number of PIV image pairs that can be taken is one thousand. The average velocities have been computed on 50 consecutive image pairs, corresponding to time intervals of $5 \mathrm{~s}$. The combustion of the materials also involves swelling and twisting of the samples, requiring a special post-treatment to adjust the wall position on PIV images. Figure 10 shows the axial and radial components of the velocity at three different locations for the $4.5 \mathrm{~mm}$ thick composite material and for the steel plate. Other test cases (not shown) performed on the $2 \mathrm{~mm}$ thick composite samples present also similar velocity profiles.

There are strong similarities between the reactive and inert cases. These measurements show no effect of the pyrolysis gazes on the flow near the wall. Knowing the mass loss of the composite sample [18], it is possible to estimate a velocity value of the pyrolysis gases emitted at the sample surface. This 
calculation shows that the pyrolysis gases have a velocity which is of the order of $1 \%$ of the bulk velocity at the tube outlet, so well below the velocity values of the hot gases.
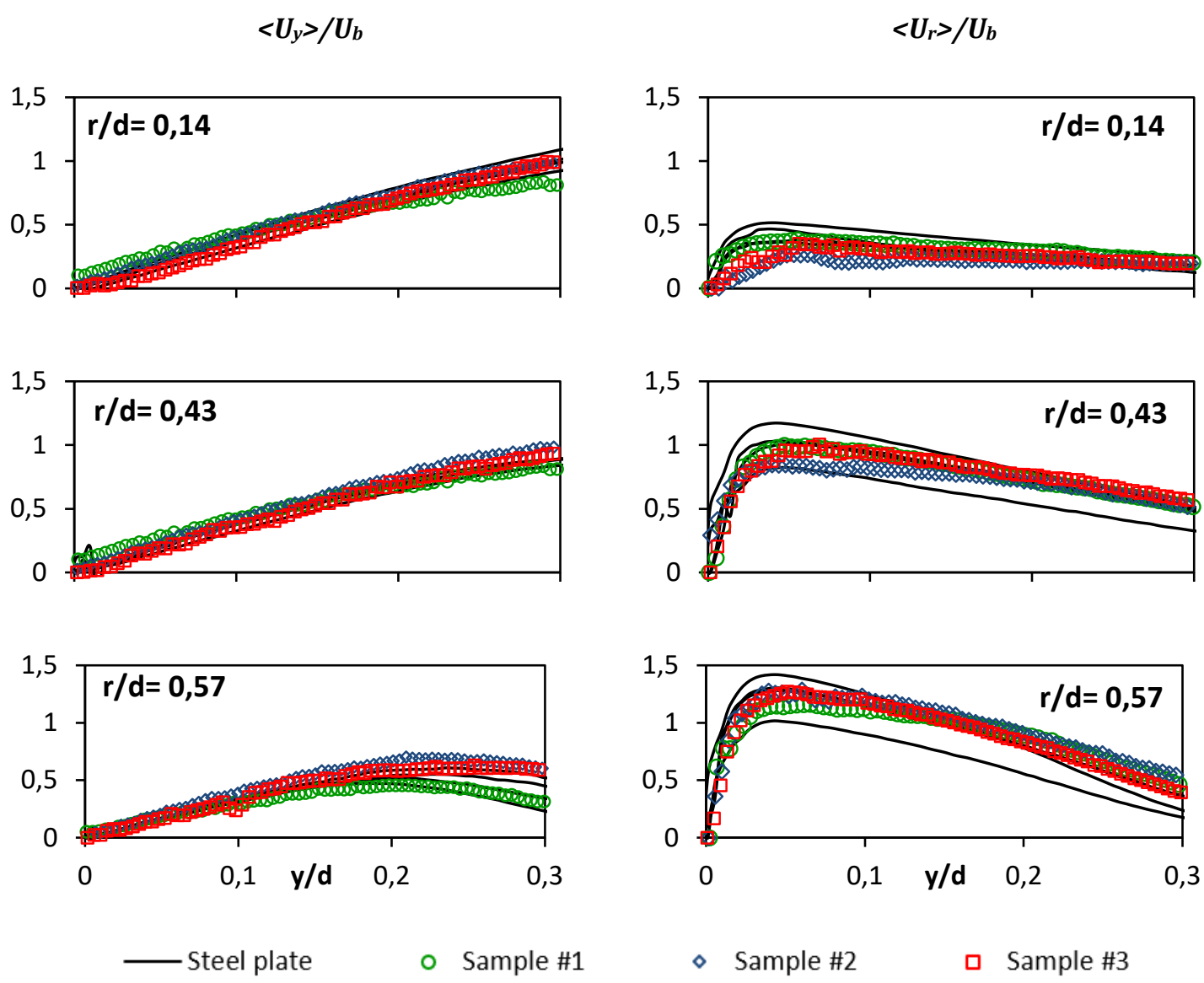

Figure 10 : Comparison of the mean axial and radial velocity for four measurements on steel plate (plain lines) and three samples of $4.5 \mathrm{~mm}$ thick composite (symbols).

\subsection{Heat flux measurements}

The total heat flux $q_{\text {net }}$ and the radiative part of the heat flux $\alpha_{\text {sensor }} q_{\text {irr }}$ have been measured using the water-cooled Gardon gauge respectively with and without the $\mathrm{CaF}_{2}$ window. The temperature of the gauge during the experiments is stable after a few seconds and does not exceed $325 \mathrm{~K}$. The heat flux measured with the window corresponds to $q_{i r r}=23.5 \mathrm{~kW} \cdot \mathrm{m}^{-2}$ assuming a 0.94 absorptivity for the sensor. The total heat flux is $q_{n e t}=106 \mathrm{~kW} \cdot \mathrm{m}^{-2}$. These two values allow the calculation of the Nusselt number with the equations (2) and (3) and the result is $N u_{\exp }=23.1$.

\section{Analytical considerations}

The conditions for the hot impinging jet used in this work are: low values of the $H / d$ ratio (0.5), a small Reynolds number (1500), but a high temperature $(1635 \mathrm{~K})$. This last value implies that there is an important thermal gradient near the wall which may have an influence on the velocity profiles. In order to evaluate this, the analytical solution proposed by Schlichting [19] in the case of isothermal jets is compared to the velocity measurements. In addition, one can wonder whether existing models, presented in the introduction, are relevant to calculate the Nusselt number at the stagnation point as well as the convective heat flux. Finally, the high temperature of the fluid induces a high viscosity. Then, it is relevant to study the influence of the viscosity on the flow dynamics by comparing the experimental results with the values given by the analytical relations with or without viscous terms as proposed by Remie [12,13]. 
The analytical relations used herein need to know the thermophysical properties of the hot gas. They are calculated with the software CEArun [20], at temperature 1635K. The hot gas is assumed to be composed of the products of the stoichiometric reaction of propane with air. The results are shown in Table 2.

Table 2 : Thermophysical properties of the gas calculated with CEArun at temperature 1635K.

\begin{tabular}{ccccccc}
\hline$\rho$ & $\begin{array}{c}\mu \\
\left(\mathrm{kg} \cdot \mathrm{m}^{-3}\right)\end{array}$ & $\begin{array}{c}\left.\mathrm{kg}_{\mathrm{m}}^{-1} \cdot \mathrm{s}^{-1}\right) \\
\left(\mathrm{m}^{2} \cdot \mathrm{s}^{-1}\right)\end{array}$ & $\begin{array}{c}C_{p} \\
\left(\mathrm{~J} \cdot \mathrm{kg}^{-1} \cdot \mathrm{K}^{-1}\right)\end{array}$ & $\begin{array}{c}k \\
\left(\mathrm{~W} \cdot \mathrm{m}^{-1} \cdot \mathrm{K}^{-1}\right)\end{array}$ & $\begin{array}{c}\alpha \\
\left(\mathrm{m}^{2} \cdot \mathrm{s}^{-1}\right)\end{array}$ & $P r$ \\
\hline 0,295 & $5,61.10^{-5}$ & $2,54.10^{-4}$ & $1,25.10^{3}$ & 0.1 & $2,73.10^{-4}$ & 0.697 \\
\hline
\end{tabular}

\subsection{High temperature isothermal flow}

The plain lines plotted on the mean axial velocity profiles in Figure 7 show, close to the wall, an almost linear decrease with a slope $\beta_{y}=\partial\left(\frac{U_{y}}{U_{b}}\right) / \partial\left(\frac{\mathrm{y}}{\mathrm{d}}\right)$ equal to 3.13 for $r / d<0.5$. The radial velocity measurements show a boundary layer profile which is characterised by a thickness $\delta_{v}^{\text {exp }}$, and which is almost constant for $r / d<0.5$ and evaluated to $0.047 y / d$. For $y / d=\delta_{v}$ exp, the radial speed is linearly increasing with $r$, and $\beta_{r}=\partial\left(\frac{U_{r}}{U_{b}}\right) / \partial\left(\frac{r}{d}\right)$ is equal to 1.85 .

Table 3 : Experimental and analytical values of the velocity gradients $\beta_{y}$ and $\beta_{r}$, and the boundary layer thickness $\delta_{v}$.

\begin{tabular}{|c|c|c|c|c|c|}
\hline$\beta_{y}{ }^{\exp }$ & $\beta_{r}^{\exp }$ & {$\left[\beta_{y} / \beta_{r}\right]^{\exp }$} & {$\left[\beta_{y} / \beta_{r}\right]^{\text {theo }}$} & $\delta_{v} \exp$ & $\delta_{\mathrm{V}}^{\text {theo }}$ \\
\hline 3.13 & 1.85 & 1.7 & 2 & 0.047 & 0.044 \\
\hline
\end{tabular}

The analytical solution for the velocity in an axisymmetric, isothermal and laminar impinging jet has been developed by Schlichting [19]. The solution predicts a constant velocity gradient in the inviscid zone, and such as $\beta_{y}=2 \beta_{r}$.

The thickness of the sub-layer $\delta_{v}$, that has been defined earlier, is also related to the axial velocity gradient $\beta_{y}$ and is given by eq. (6) where the A factor can be taken between 1.98 and 2.8 depending on the definition of the boundary layer thickness $[19,21]$.

$$
\delta_{v}=A \sqrt{\frac{\beta_{y}}{v}}
$$

Based on eq. (6), $\delta_{v}$ theo is calculated using the values of $\beta_{y}$ given by the PIV measurements. The measured and calculated values for the sub-layer thicknesses are given in Table 3 . The characteristics of the flow near the wall are well predicted by the isothermal theory using the hot flow temperature $T=1635 \mathrm{~K}$, the velocity gradients are constant near the wall and the measured sub-layer thickness is constant and close to the theoretical value. However, a difference between the theory and the experiment is noticed for the ratio $\beta_{y} / \beta_{r}$, the observed value is less than twice. This deviation from the theory can be explained by the nature of the jet. Indeed, the characterisation of the outlet jet shows that the flow has fluctuations since the $\left\langle U_{y}{ }^{R M S}\right\rangle / U_{b}$ ratio is around 0.2 , while the Schilchting solution is for a laminar flow. Moreover, the jet and the wall are not isothermal. 


\subsection{Viscosity effect on the velocity profile close to the wall}

A previous analysis has been done by Remie [12,13] on an impinging laminar flame jet, providing analytical relations for the velocity profiles close to the wall. In his work, the jet at the top of the flame is approximated by an inert hot plug flow with $\mathrm{H}$ being the distance between the tip of the flame and the wall. In a first approach, the velocity profiles are calculated using the dominant terms of the balance equations and neglecting the viscous terms. In a second approach, the calculation is made considering a viscous flow. Near the wall, the axial velocity $U_{y}$ is described by the eq. (7) in the non-viscous approach and by the eq. (8) with the viscous terms. The term $y_{r e f}$ is equal to zero if the viscosity is neglected and is equal to $\delta_{v} / 3$ in the other case, $\delta_{v}$ being the viscous boundary layer thickness.

$$
\begin{gathered}
U_{y}(y)=\frac{-a^{2}}{4 U_{\max }}\left(y+y_{r e f}\right)^{2}-a\left(y+y_{r e f}\right) \\
U_{y}(y)=a \delta_{v}\left(\frac{y^{3}}{3 \delta_{v}{ }^{3}}+\frac{y^{2}}{\delta_{v}{ }^{2}}\right)
\end{gathered}
$$

In the boundary layer and very close to the wall, the hot flows on the steel plate or on the composite samples are laminar, and the previous relations may apply. For $y / \delta_{v}<<1$, only the first terms, $y$ in eq. (7) and $y^{2}$ in eq. (8), must be considered. In the present work, the strain rate a is given by $2 \mathrm{U}_{\mathrm{b}} / \mathrm{H}$, with $H$ being the distance between the hot flow exit and the wall, and the $\delta_{v}$ value being the experimental one shown in Table 3.

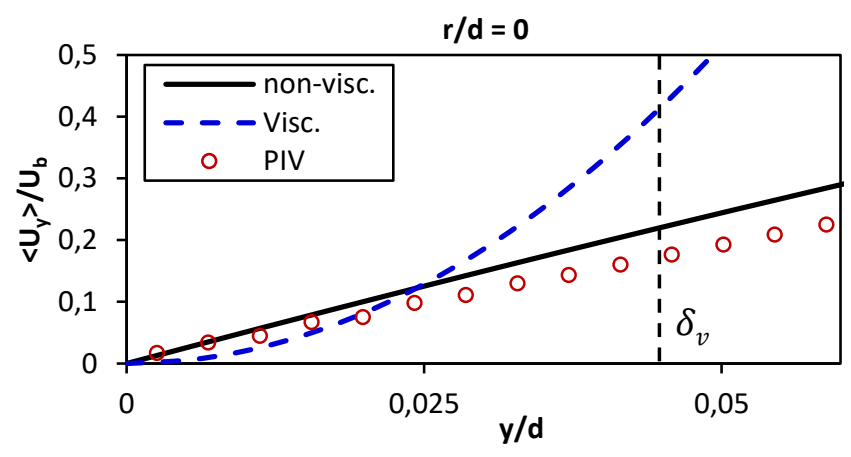

Figure 11 : Comparison between the experimental velocity profile and the two Remie's laws close the stagnation point.

The calculated velocities are reported in Figure 11 and compared with the measured values. They show that the agreement is better with the linear profile, indicating that there is little influence of the viscous effects close to the wall.

\subsection{Heat flux at the stagnation point}

As described in the state of the art, an extensive number of studies have been performed on impinging jets and wall heat transfer, this last one depending on the parameters such as the wall/burner distance, the Reynolds number or the turbulence intensity. In this study, the low value of the Reynold's number $\left(R_{e}=1500\right)$ implies that the jet is in the transitional regime, between laminar and fully turbulent regimes. Thus, various models can be used to calculate the heat flux at the stagnation point. For comparison, the authors have selected three models from the literature corresponding to a laminar (eq. (9)), a transitional (eq. (10)) and a turbulent regime (eq. (11)). The first equation corresponds to the analytical resolution of an inviscid, and axisymmetric jet impinging on a flat wall [9]. The two other equations [22,23] are derived from the first one to include the effect of the turbulence.

$$
N u_{0}^{L a m}=0.763 d \operatorname{Pr}^{0.4}\left(\frac{U_{b}}{\pi d v}\right)^{0.5}
$$




$$
\begin{gathered}
N u_{0}^{\text {Trans }}=0.56 R e^{0.492} \\
N u_{0}^{T u r b}=0.65 R e^{1 / 2}+2.03\left(\frac{T u R e}{100}\right)-2.46\left(\frac{T u R e^{3 / 4}}{100}\right)^{2}
\end{gathered}
$$

Using the above equations, the Nusselt number is evaluated as follow:

$$
\begin{aligned}
& N u_{0}^{\text {Lam }}=28.1 \\
& N u_{0}^{\text {Trans }}=20.5 \\
& N u_{0}^{\text {Turb }}=38.7
\end{aligned}
$$

Equations (9) and (10), for respectively the laminar and transitional regimes, give values that are in good agreement with the experimental one equal to 23.1, obtained with the method described in section 3.4. In eq. (11), one must know the turbulence intensity $T u$. The representative value at the nozzle output is about $20 \%$ (see Figure 8). This gives a Nusselt number equal to 38.7, which overestimates the experimental value at the stagnation point by almost $67 \%$. The rather good agreement with Sibulkin's theory [7] tends to indicate that the jet could be considered as laminar. However, the axial velocity fluctuations measured at the burner outlet are not negligible. Nevertheless, they are attributed to lowfrequency pulsations in the flame tube and do not seem to significantly affect the transfer to the wall. In conclusion, the value calculated with eq. (10) is the closest result to the experimental value, suggesting that the analytical relations for the transitional regime describe well the impinging flow.

\section{Conclusion}

The properties of a high-temperature gas jet, produced by a propane burner and impinging flat samples of steel or composite material, have been analysed experimentally. The velocity profiles have been determined in the jet outlet and close to the walls using the Particle Image Velocity laser technique. The temperatures in the flow have been measured with a thin thermocouple. Experimental results reproduce well the main characteristics that are observed in the stagnation and wall jet zones of such impinging flows. Close to the wall and in the stagnation zone, the axial velocity is linearly decreasing, and the boundary layer thickness is constant with maximum radial velocity increasing also linearly with the distance to the jet axis. The velocity profiles observed with the composite sample are very close to the ones obtained with the steel plate, indicating that the pyrolysis gas emission has no influence on the flow structure close to the wall. In the present work, with a plate at short distance to the burner outlet $(H / d=0,5)$ and a low Reynolds number value $(R e=1500)$, it has been found that the Nusselt number at the stagnation point is proportional to the square root of Reynolds number, indicating that the initial turbulence produced inside the burner has little influence on the heat flux on the wall.

\section{Acknowledgements}

The authors acknowledge the EU for financially supporting the AircraftFire Project under Grant No 265612. The authors also thank C. Gobin and A. Vandel for helping with the PIV experiments.

\section{References}

[1] ISO 2685, "Resistance to fire in designated fire zones," 1998.

[2] AC 20-135 chg 1, "Powerplant Installation and Propulsion System Component Fire Protection Test Methods, Standards and Criteria," 2018.

[3] R. Viskanta, "Heat transfer to impinging isothermal gas and flame jets," Experimental Thermal and Fluid Science, vol. 6, no. 2, pp. 111-134, Feb. 1993, doi: 10.1016/0894-1777(93)90022-B.

[4] S. Polat, B. Huang, A. S. Mujumdar, and W. J. M. Douglas, "Numerical flow and heat transfer under impinging jets: a review," Annual review of heat transfer, vol. 2, no. 6, pp. 157-197, 1989. doi: 10.1615/AnnualRevHeatTransfer.v2.60. 
[5] C. D. Donaldson, R. S. Snedeker, and D. P. Margolis, "A study of free jet impingement. Part 2. Free jet turbulent structure and impingement heat transfer," Journal of Fluid Mechanics, vol. 45, no. 3, pp. 477-512, 1971, doi: 10.1017/S0022112071000156.

[6] D. Lytle and B. W. Webb, "Air jet impingement heat transfer at low nozzle-plate spacings," International Journal of Heat and Mass Transfer, vol. 37, no. 12, pp. 1687-1697, Aug. 1994, doi: 10.1016/0017-9310(94)90059-0.

[7] M. J. Tummers, J. Jacobse, and S. G. J. Voorbrood, "Turbulent flow in the near field of a round impinging jet," International Journal of Heat and Mass Transfer, vol. 54, no. 23, pp. 4939-4948, Nov. 2011, doi: 10.1016/j.ijheatmasstransfer.2011.07.007.

[8] P. Grenson, O. Léon, P. Reulet, and B. Aupoix, "Investigation of an impinging heated jet for a small nozzle-to-plate distance and high Reynolds number: An extensive experimental approach," International Journal of Heat and Mass Transfer, vol. 102, pp. 801-815, Nov. 2016, doi: 10.1016/j.ijheatmasstransfer.2016.06.076.

[9] M. Sibulkin, "Heat transfer near the forward stagnation point of a body of revolution," Journal of the Aeronautical Sciences, vol. 19, no. 8, pp. 570-571, Aug. 1952, doi: 10.2514/8.2383.

[10] T. H. van der Meer, "Stagnation point heat transfer from turbulent low reynolds number jets and flame jets," Experimental Thermal and Fluid Science, vol. 4, no. 1, pp. 115-126, Jan. 1991, doi: 10.1016/0894-1777(91)90025M.

[11] G. K. Hargrave, M. Fairweather, and J. K. Kilham, "Forced convective heat transfer from premixed flames -Part 2: Impingement heat transfer," International Journal of Heat and Fluid Flow, vol. 8, no. 2, pp. 132-138, Jun. 1987, doi: 10.1016/0142-727X(87)90013-0.

[12] M. J. Remie, M. F. G. Cremers, K. R. A. M. Schreel, and L.P. H. de Goey, "Analysis of the heat transfer of an impinging laminar flame jet," International Journal of Heat and Mass Transfer, vol. 50, no. 13, pp. 2816-2827, Jul. 2007, doi: 10.1016/j.ijheatmasstransfer.2006.10.053.

[13] M. J. Remie et al., "Heat-transfer distribution for an impinging laminar flame jet to a flat plate," International Journal of Heat and Mass Transfer, vol. 51, no. 11-12, pp. 3144-3152, 2008, doi: 10.1016/j.ijheatmasstransfer.2007.08.036.

[14] Robert Gardon, "An instrument for the direct measurement of intense thermal radiation," Review of Scientific Instruments, vol. 24, no. 5, pp. 366-369, 1953, doi: https://doi.org/10.1063/1.1770712.

[15] G. M. Carlomagno and A. laniro, "Thermo-fluid-dynamics of submerged jets impinging at short nozzle-to-plate distance: A review," Experimental Thermal and Fluid Science, vol. 58, pp. 15-35, Oct. 2014, doi: 10.1016/j.expthermflusci.2014.06.010.

[16] D. Bradley and K. J. Matthews, "Measurement of high gas temperatures with fine wire thermocouples," Journal of Mechanical Engineering Science, vol. 10, no. 4, pp. 299-305, 1968, doi: 10.1243/jmes_jour_1968_010_048_02.

[17] P. Tranchard et al., "Fire behaviour of carbon fibre epoxy composite for aircraft: Novel test bench and experimental study," Journal of Fire Sciences, vol. 33, no. 3, pp. 247-266, 2015, doi: 10.1177/0734904115584093.

[18] E. Schuhler, A. Coppalle, B. Vieille, J. Yon, and Y. Carpier, "Behaviour of aeronautical polymer composite to flame: A comparative study of thermoset- and thermoplastic-based laminate," Polymer Degradation and Stability, vol. 152, pp. 105-115, 2018, doi: 10.1016/j.polymdegradstab.2018.04.004.

[19] H. Schlichting, Boundary layer theory. Springer, 1979.

[20] C. Snyder, "https://cearun.grc.nasa.gov/." .

[21] X. S. Wang, Z. Dagan, and L. M. Jiji, "Conjugate heat transfer between a laminar impinging liquid jet and a solid disk," International Journal of Heat and Mass Transfer, vol. 32, no. 11, pp. 2189-2197, Nov. 1989, doi: 10.1016/0017-9310(89)90125-7.

[22] L. L. Dong, C. S. Cheung, and C. W. Leung, "Heat transfer from an impinging premixed butane/air slot flame jet," International Journal of Heat and Mass Transfer, vol. 45, pp. 979-992, Feb. 2002, doi: 10.1016/S00179310(01)00215-0.

[23] C. J. Hoogendoorn, "The effect of turbulence on heat transfer at a stagnation point," International Journal of Heat and Mass Transfer, vol. 20, no. 12, pp. 1333-1338, Dec. 1977, doi: 10.1016/0017-9310(77)90029-1. 